Original Article

\title{
CORRELATION OF SERUM ALBUMIN AND CREATININE WITH OXIDATIVE STRESS MARKERS IN PATIENTS HAVING NEPHROTIC SYNDROME
}

\author{
GLORY S. PARMAR ${ }^{1}$, KINNARI N. MISTRY1 ${ }^{*}$, SISHIR GANG ${ }^{2}$
}

${ }^{1}$ Department of M. Sc Integrated Biotechnology, Ashok and Rita Patel Institute of Integrated, Study and Research in Biotechnology and Allied Sciences, Vallabh Vidyanagar, 388121, Anand, Gujarat, India, 'Department of Nephrology, Muljibhai Patel Urological Hospital, Dr. V. V. Desai Road, Nadiad, 387001, Gujarat, India

Email: kinnarimistry@aribas.edu.in

Received: 21 Aug 2021, Revised and Accepted: 16 Oct 2021

\begin{abstract}
Objective: Children with nephrotic syndrome (NS) have a stressful condition, and oxidative damage may impair their treatment response. This study aims to gain a better understanding of the relationship between oxidative stress and NS to lay the basis for further research into improved diagnostic options, treatment, and prevention of the disease.

Methods: We took a blood sample from 100 Indian patients aged 2-14 y. Each patient was tested for oxidative stress. The buege method was used to assess MDA levels in patients. The pyrogallol method was used to measure SOD activity in blood serum, and the jollow method was used to measure glutathione levels.

Results: The levels of oxidative stress markers (MDA, SOD, and GSH) were compared between NS patients and the control. SOD and GSH concentrations were significantly decreased in the NS group when compared to the control. In contrast, MDA level was significantly higher in the NS group than in the control. In the correlation analysis, we found that the serum SOD activity was significantly positively correlated with serum albumin and creatinine level in patients with NS. Thus, oxidative stress in children with NS is indicated by reduced antioxidant potential because of low albumin. Therefore, it is thought that oxidative stress is implicated in the development of NS in Indian children.
\end{abstract}

Conclusion: We concluded that oxidative stress was intensified in children with NS due to decreased antioxidant levels caused by hypoalbuminemia.

Keywords: Nephrotic Syndrome (NS), Oxidative stress, Malondialdehyde (MDA), Glutathione (GSH), Superoxide Dismutase (SOD), Indian children

(C) 2021 The Authors. Published by Innovare Academic Sciences Pvt Ltd. This is an open access article under the CC BY license (https://creativecommons.org/licenses/by/4.0/) DOI: https://dx.doi.org/10.22159/ijpps.2021v13i12.42931. Journal homepage: https://innovareacademics.in/journals/index.php/ijpps.

\section{INTRODUCTION}

Free radical-induced oxidative damage has been implicated in various clinical diseases [1], including kidney injury. Oxidative stress is described as an imbalance between the oxidation and antioxidation processes resulting in highly reactive molecules, primarily reactive oxygen species, being produced and cleared (ROS). According to studies, children with nephrotic syndrome experience oxidative stress (NS) [2]. The albumin protein mediates the majority of the antioxidant activity in plasma and serum. Human serum albumin was responsible for $70 \%$ of the free radical trapping activity (HSA) [3]. Renal perfusion decreases due to a reduction in intravascular volume. As a consequence, the glomerular filtration rate (GFR) is reduced. One of the investigations of renal failure in children with NS is a decrease in GFR [4]. Evaluation of GFR provides a clue for overall renal function, which is crucial in children having NS due to its rapid progression to acute renal failure. The feasible method to estimate GFR is to measure serum creatinine level [5]. For many decenniums, alteration between oxidants and antioxidants generates oxidative stress, which is intricate in developing several acquired/genetic diseases, including NS [6]. The pathogenesis of insufficient protein permeability and other NS difficulties is still unknown. The finding that reactive oxygen species (ROS) can act as mediators of glomerular injury advances our understanding of the disease's etiology significantly [7]. NS has also been related to increased oxidative stress in numerous studies [8, 9]. MDA (Malondialdehyde), GSH (Glutathione), and SOD (Superoxide Dismutase) are all readily quantifiable markers of oxidative stress [8]. MDA is the by-product of lipid peroxidation, which is used to check the status of ROS indirectly. SOD does damage to the superoxide radical by dismutating it into peroxide [10]. Kidneys rely on an adequate supply of GSH for their normal functioning [11]. Thus, serum albumin, creatinine, SOD, MDA, and blood GSH level have a significant role in the vulnerability of these children to diseased conditions. This research aimed to highlight the role of oxidative stress in NS children. Excessive production of reactive oxygen species (ROS) is one of the possible causes of oxidative stress (ROS) associated with kidney injury.

\section{MATERIALS AND METHODS}

Study Participants: This research was carried out on nephrotic syndrome patients in India. The participants were split into two groups: (A) Children suffering from Nephrotic syndrome (B) Individuals who are healthy (Age: 2-14 y). Inclusion criteria: Renal insufficiency was defined as a glomerular filtration rate (GFR) less than $80 \mathrm{ml} / \mathrm{min}$, a urine protein excretion larger than $0.05 \mathrm{~g} / \mathrm{kg}$ per $24 \mathrm{~h}$, and serum albumin less than $25 \mathrm{~g} / \mathrm{l}$. NS patients diagnosed with other systemic disorders were excluded from this study. Pediatric nephrologists made the diagnosis of NS at the authorized center of Muljibhai Patel Urological Hospital. The Institutional Ethics Committee of G. J. Patel Ayurvedic College, Vallabh Vidyanagar, Gujarat, approved this study (Approval No-IEC-4/GJPIASR/201718/08). Informed consent forms were signed before performing the experiments.

\section{Sample collection}

Blood samples were collected in a vacutainer serum tube from Muljibhai Patel Urological Hospital Nadiad. After taking a blood sample, the serum was isolated from the blood and centrifuged for $10 \mathrm{~min}$ at 3200-3500 rpm; to obtain the red blood cells. From the fresh sample, oxidative stress markers like MDA, SOD, and GSH were estimated. Malondialdehyde (MDA) level in patients was checked using the buege method [12]. Superoxide dismutase (SOD) activity from blood serum was checked using the pyrogallol method [13]. Glutathione level in blood was measured using jollow's method [14]. 


\section{Estimation of GSH}

Jollow's methods were used to test blood glutathione. $200 \mu \mathrm{l}$ of blood, $0.8 \mathrm{ml}$ of $\mathrm{D} / \mathrm{W}$, and $0.5 \mathrm{ml}$ of $10 \%$ Sulfosalicylic acid were mixed. The mixture was vortexed and centrifuged @ 3000rpm for $10 \mathrm{~min} ; 0.5 \mathrm{ml}$ of supernatant was added in $4.5 \mathrm{ml}$ of $0.5 \mathrm{M}(\mathrm{pH} 8.23)$ Tris phosphate buffer and $0.5 \mathrm{ml}$ of 5,5-Dithiobis (2-nitro benzoic acid). The reaction mixture formed yellow color, which was read at $412 \mathrm{~nm}$.

\section{Estimation of MDA}

$1 \mathrm{ml}$ serum was treated with $2 \mathrm{ml}$ TCA-TBA-HCL and thoroughly mixed. The reaction solution was heated for $15 \mathrm{~min}$ and then centrifuged for $10 \mathrm{~min}$ at $1000 \mathrm{~g}$. The coloring complex developed in the supernatant was measured at $535 \mathrm{~nm}$ against a blank. Blank included all the reagents except the serum sample.

\section{Estimation of SOD}

The inhibition of pyrogallol autoxidation was used to determine SOD activity in serum samples, defined by Marklund [13]. $1 \mathrm{ml}$ serum sample, $0.1 \mathrm{ml}$ pyrogallol reagent, and $1.9 \mathrm{ml}$ tris buffer were mixed. After a 90 -second induction time, the inhibition of pyrogallol was calculated every 30 seconds for 3 min at a wavelength of $420 \mathrm{~nm}$.

\section{Statistical analysis}

SPSS version 21.0 was used to conduct the statistical analysis. Comparison between control and nephrotic syndrome group was done by student $t$-test.

\section{RESULTS}

There is no noticeable difference in age between NS patients and controls. However, the NS group had considerably lower serum albumin and creatinine levels than the control group $(\mathrm{p}<0.05)$, the NS group had a higher UPCR ratio $(\mathrm{p}<0.05)$. On the other hand, the serum cholesterol level was normal in both groups (table 1).

MDA levels in the serum were substantially higher in NS patients than controls $(\mathrm{P}<0.05)$. The activity of SOD was markedly higher in control patients than in NS patients $(\mathrm{p}<0.05)$. GSH concentrations were substantially lower in NS patients than in the control group $(\mathrm{p}<0.05)$ (table 2). In patients with NS, a significant positive relationship between SOD activity and serum albumin and creatinine levels was observed $(\mathrm{P}<0.05)$. No significant association was seen when serum albumin and creatinine levels were compared to MDA and GSH levels (p>0.05) (fig. 1, 2, 3).

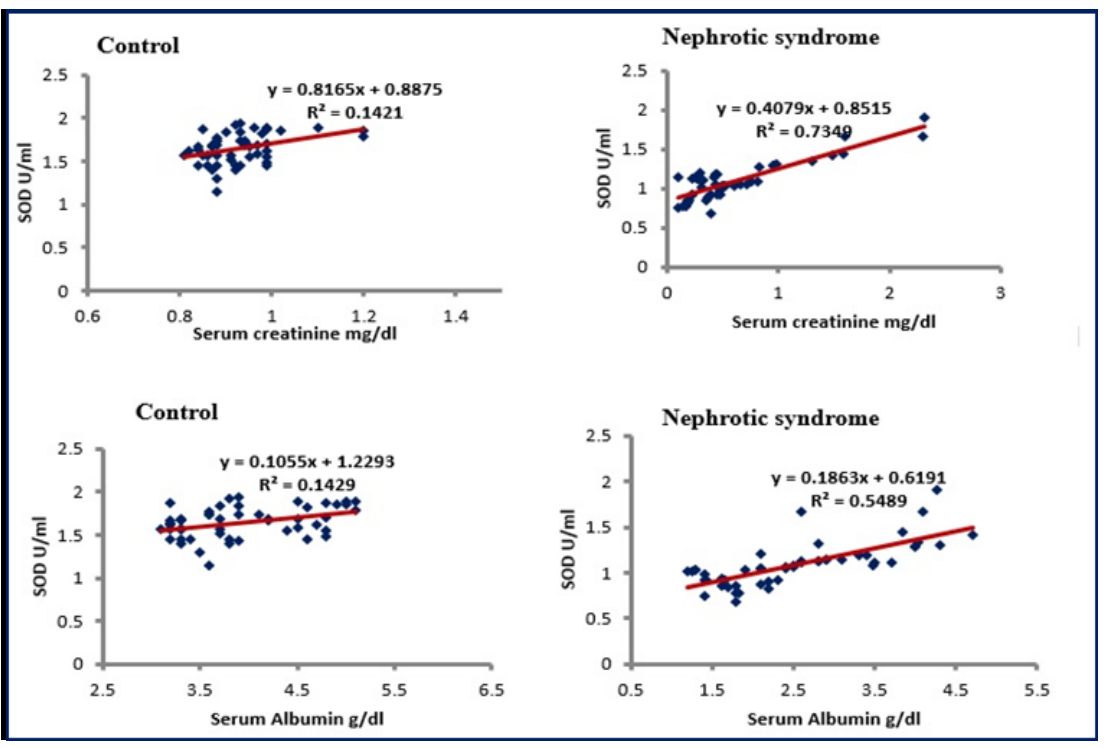

Fig. 1: Correlation of serum albumin, serum creatinine with SOD (superoxide dismutase) activity
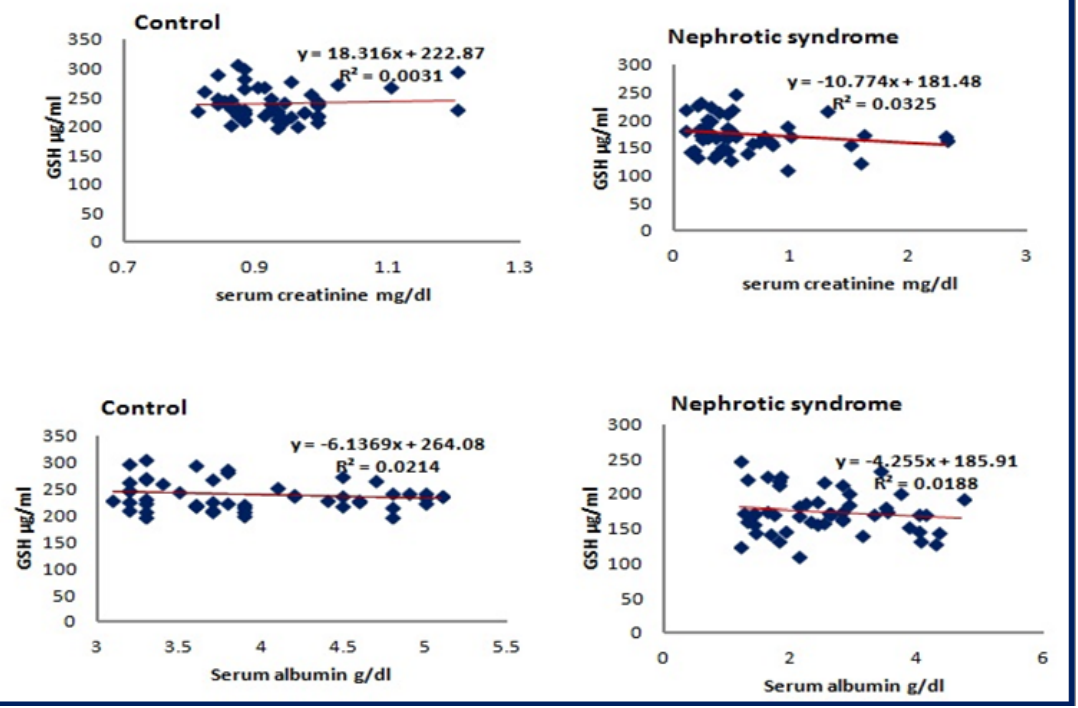

Fig. 2: Correlation of serum albumin, serum creatinine with GSH (glutathione) levels in the blood 


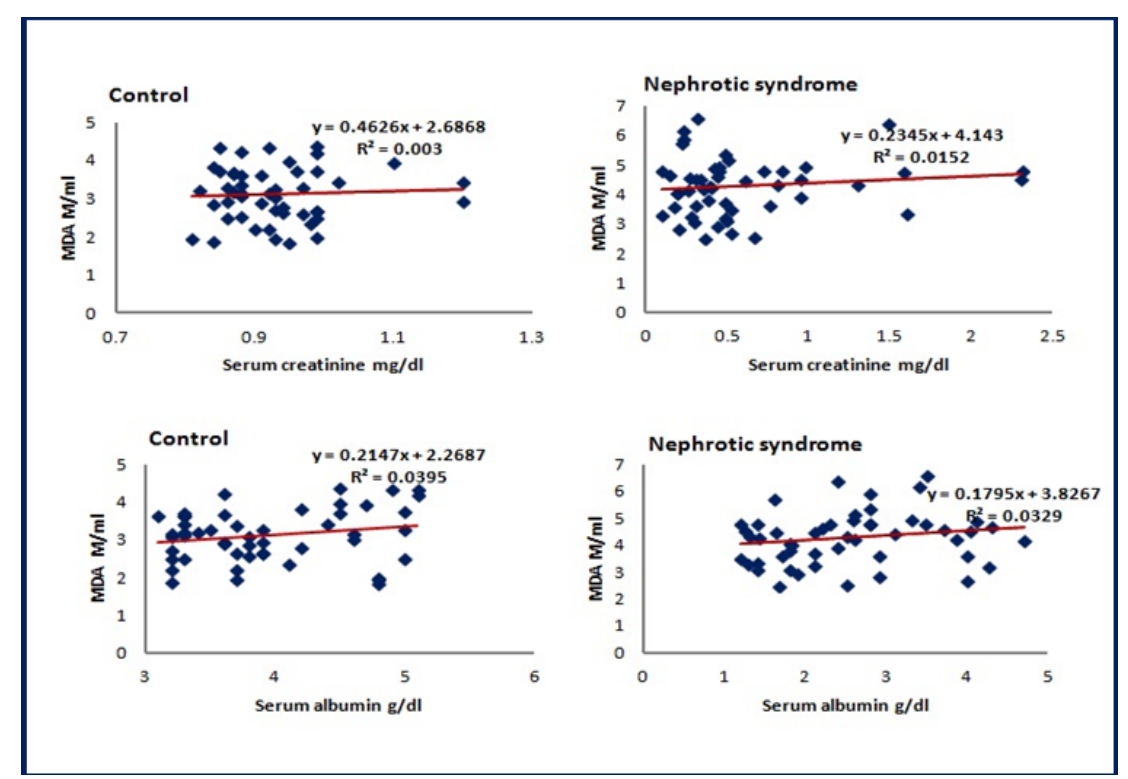

Fig. 3: Correlation of serum albumin, serum creatinine with MDA (Malondialdehyde) levels

\section{DISCUSSION}

The glomerular basement membrane is degraded by superoxidemediated oxidative damage, and denovo proteoglycans synthesis is reduced [15]. The Glomerular Filtration Barrier (GFB) is negatively charged by heparan sulfate, a proteoglycan, and thus repels the transport of negatively charged molecules. Oxidative damage to heparan sulfate may lead to increase glomerular permeability. Therefore, glomerular injury due to ROS may be responsible for the pathogenesis of glomerular diseases [16]. Clinical data of the participants suggest that creatinine clearance is helpful in clinical practice to measure glomerular filtration rate, and decline in serum albumin level indicates reduced antioxidant level. Urine protein/Creatinine ratio and serum cholesterol level are significantly different in both groups. Many clinical disorders are caused due to oxidative damage by free radicals. Lipid peroxidation enhances protein permeability in the glomerulus and impairs the structural integrity of tubular epithelial cells due to the formation of reactive oxygen species (ROS). It is also reported that ROS is responsible for the pathogenesis of childhood nephrotic syndrome [17]. One of the possible factors which are responsible for damage in DNA is ROS. The rapid injury and damage to DNA caused by ROS result in proteinuria and subsequent glomerulosclerosis [18]. Many illnesses, including cancer, heart disease, diabetes, aging, liver, kidney, and lung disorders, are influenced by oxidative stress [19].

Table 1: Clinical characteristic of selected participants

\begin{tabular}{llll}
\hline Parameters & Control & Nephrotic syndrome & $p$-Value \\
\hline Age & $8.72 \pm 4.81$ & $7.12 \pm 4.57$ & - \\
S/P Creatinine mg/dl & $1.099 \pm 0.066$ & $0.467 \pm 0.048$ & $<0.05$ \\
S/P Serum Albumin g/dl & $4.459 \pm 0.09$ & $2.9168 \pm 0.133$ & $<0.05$ \\
Urine protein/Creatinine ratio (UPCR):1 & $0.2518 \pm 0.028$ & $3.1604 \pm 0.657$ & $<0.05$ \\
S/P Cholesterol mg/dl & $116.7225 \pm 6.954$ & $91.733 \pm 1.726$ & $<0.05$ \\
\hline
\end{tabular}

S, Serum; P, Protein; $p$-Value $<0.05$ considered as significant; Data were in mean \pm SD. Significant value for student $t$-test was considered $<0.005$ ( $\mathrm{p}$-value).

The assessment of lipid peroxidation status is an essential criterion in determining the degree of oxidative stress. Studies have indicated that free radical lipid peroxidation can harm the cell membrane and create enzymatic and receptor binding membrane activity abnormalities, resulting in damage to the organ [20]. The majority of phospholipids on the membrane are readily oxidized, resulting in lipid peroxide, which decomposes to aldehyde like MDA [21]. Our investigation discovered that the NS group had a significantly higher MDA level than the control group. Similarly, another study revealed a rise in the MDA level in NS compared to the control group [6-7, 9]. Turi et al. reported that eight children with post-streptococcal glomerulonephritis in the acute stage had significantly increased plasma MDA and decreased erythrocyte SOD activity compared to healthy controls [22]. Additionally, Templar et al. [23] demonstrated that patients with chronic renal failure due to chronic glomerulopathies had significantly higher plasma MDA levels than those with non-glomerular diseases, implicating a role for oxidative stress in the pathogenesis of glomerular injury [23]. Another study discovered a fourfold increase in the amount of MDA in the blood [24].

The superoxide radical produced by active neutrophils is required for the neutrophil-mediated acute inflammatory response, which results in severe tissue damage [25]. Superoxide dismutase has been found as a molecule that acts as an anti-inflammatory and anti-superoxide scavenger [26]. Bulbul et al. discovered that the antioxidant enzyme SOD had a similar activity at disease start, during remission, and in control participants [27]. SOD is also expected to increase in response to excessive oxidative damage, compensating for and protecting tissue damage [28]. Thus, the absence of an increase in acute stage SOD activity could result from oxidative stress-induced depletion, as demonstrated by increasing MDA levels.

Glutathione is the most potent antioxidant that is found in every cell [29]. It is a thiol-containing tripeptide found in high concentrations in live cells in its reduced form (GSH). When it comes into contact with reactive oxygen species (ROS), it is oxidized to glutathione radical, regenerated to its reduced form via glutathione reductase activity. We noticed a significant decrease in GSH concentrations in the patients' group, ascribed to increased reactive oxygen species generation, converting the reduced form to the oxidized form (GSSH). Glutathione peroxidase (GPx), glutathione-S-transferase (GST), and glutathione reductase all use GSH as a substrate (GRx). The decrease in concentrations may be due to the increased turnover of GSH required to prevent oxidative damage under these 
conditions [30]. Previously, similar discoveries of lower GSH concentrations in nephrotic syndrome were documented [31], implying that nephrotic syndrome is related to increased oxidative stress. In contrast, nephrotic syndrome has been associated with unchanged erythrocyte GSH concentrations [6].

Our antioxidant and oxidant status results were well supported by a study done by the reddy's group in 2016. They found a significantly increased level of MDA and decreased the level of SOD activity and GSH in NS patients [8]. In contrast, another study found unaltered GSH concentrations and increased SOD concentration in children with NS $[6,17]$. We observed a statistically significant positive association between serum creatinine and SOD activity and serum albumin and SOD activity (fig. 1). Similarly, Mistry et al. also reported a positive correlation of SOD activity in Diabetic nephropathy [32]. The earlier study found that SOD is a responsible and significant mediator of the podocyte damage, causing glomerular injury influenced by puromycin and involved in many other diseases [33]. As a result, SOD activity is one of the most potent stress markers in diagnosing renal disease, including NS. No significant correlations were found in MDA and GSH levels compared with serum albumin and serum creatinine (fig. 2,3 ).

Table 2: Oxidative stress markers in the control and patients

\begin{tabular}{|c|c|c|c|c|}
\hline Parameters & Control & Nephrotic syndrome & \% change & p-Value \\
\hline $\operatorname{MDA}(\mu \mathrm{M} / \mathrm{ml})$ & $3.116 \pm 0.03$ & $4.2814 \pm 0.03$ & +137.38 & $<0.05$ \\
\hline $\mathrm{GSH}(\mu \mathrm{g} / \mathrm{ml})$ & $239.86 \pm 0.01$ & $175.12 \pm 0.02$ & -73 & $<0.05$ \\
\hline $\mathrm{SOD}(\mathrm{U} / \mathrm{ml})$ & $1.64 \pm 0.17$ & $1.092 \pm 0.24$ & -66.58 & $<0.05$ \\
\hline
\end{tabular}

Data were presented in mean \pm SD

In this investigation, the lack of association of MDA and GSH with serum albumin and creatinine levels indicated that these oxidative stress markers were not predominantly generated by renal insufficiency in NS. The antioxidative defense mechanism of superoxide dismutase regulates reactive oxygen species (ROS) (O2-). It is one of the most effective antioxidant defenses in all cells exposed to oxygen and plays a critical role in the body's antioxidant defenses [34]. Thus, elevated levels of oxidative stress and decreased antioxidant defense may be related to the development of NS. Numerous studies have established that oxidative stress plays a role in developing various diseases, including NS. As a result, excessive ROS production may contribute to the progression of renal disease [31]. Thus, determining the amount of oxidative stress produced is critical for NS prediction. In vitro investigations have revealed a crucial role in oxidative stress in the development of NS [35]. The oxidationreduction reaction of ROS can generate protein carboxylation, DNA damage and cytoskeleton disruption. The cell injury influence by ROS hampers the glomerular permeability to proteins and disorganizes the tubular epithelial cells' integrity, eventually results in NS [17]. The limitation of this study is the sample size, so additional research with larger sample size is required to properly analyze the findings reported here. This study requires a larger sample size to determine the etiology of NS in children.

\section{CONCLUSION}

The current study's findings state that the NS group has significantly greater MDA levels and lower SOD and GSH levels, and as a result, they have higher oxidative stress. Furthermore, a positive correlation was identified in SOD activity compared with serum albumin and serum creatinine level, implying that oxidative stress defined by diminished antioxidant potentials due to hypoalbuminemia exists in children with NS. Thus, oxidative stress has a role in the development of NS in children. However, the antioxidant defense mechanisms of the body, such as SOD, GSH, and serum albumin, may attempt to alleviate this damage. Additional research involving a greater number of patients is necessary to explore the findings presented here.

\section{ACKNOWLEDGMENT}

The authors are immensely thankful to CharutarVidya Mandal Vallabh Vidyanagar, Anand Agricultural University, for providing a platform for this research work. We would also like to thank the Dean and supportive staff of G. J. Patel Ayurvedic College, New Vallabh Vidya Nagar, and Muljibhai Patel Urological Hospital Nadiad, Gujarat, for providing the necessary help in this work.

\section{FUNDING}

Nil

\section{AUTHORS CONTRIBUTIONS}

Conceptualization: Kinnari N. Mistry, Sishir Gang
Methodology: Glory S. Parmar, Kinnari N. Mistry, Sishir Gang

Formal analysis and investigation: Glory S. Parmar, Kinnari N. Mistry, Sishir Gang

\section{Writing-original draft preparation: Glory S. Parmar}

Writing-Review and editing: Kinnari N. Mistry; Sishir Gang

Resources: Ashok and Rita Patel Institute of Integrated Study and Research in Biotechnology and Allied Sciences (affiliated to Sardar Patel University), Vallabh Vidyanagar, 388121, Anand, Gujarat, India; Department of Nephrology, Muljibhai Patel Urological Hospital, Dr. V. V. Desai Road, Nadiad,387001, Gujarat, India; Anand Agricultural University, Anand 388110, Gujarat, India.

\section{Supervision: Kinnari N. Mistry.}

\section{CONFLICT OF INTERESTS}

The authors declare that they have no conflict of interest.

\section{REFERENCES}

1. Gupta VK, Mallika V, Gupta Y, Srivastava DK. Oxygen-derived free radicals in clinical context. Indian J Clin Biochem. 1992;7(1):3-10. doi: 10.1007/BF02867694.

2. Bakr A, Abul Hassan SA, Shoker M, Zaki M, Hassan R. Oxidant stress in primary nephrotic syndrome: does it modulate the response to corticosteroids? Pediatr Nephrol. 2009;24(12):237580. doi: 10.1007/s00467-009-1246-2, PMID 19644712.

3. Bourdon E, Blache D. The importance of proteins in defense against oxidation. Antioxid Redox Signal. 2001;3(2):293-311. doi: 10.1089/152308601300185241, PMID 11396483.

4. Koomans HA. Pathophysiology of acute renal failure in idiopatic nephrotic syndrome. Nephrol Dial Transplant. 2001;16(2):221-4. doi: 10.1093/ndt/16.2.221.

5. Yared A, Ichikawa I. Glomerular circulation and function. In: Barrat Tm, Avner ED, Harmon WE. editors. Pediatric nephrology. $4^{\text {th }}$ ed. Baltimore: Lippincott Williams and Wilkins: 1999. p. 39-55.

6. Kinra S, Rath B, Kabi BC. Indirect quantification of lipid peroxidation in steroid-responsive nephrotic syndrome. Arch Dis Child. 2000;82(1):76-8. doi: 10.1136/adc.82.1.76, PMID 10630920.

7. Kashgarian M, Sterzel RB. The pathobiology of the mesangium. Kidney Int. 1992;41(3):524-9. doi: 10.1038/ki.1992.74, PMID 1573822.

8. Reddy P, Sindgikar S, Shenoy R, Shenoy V. Oxidative stress in childhood steroid-sensitive nephrotic syndrome and its correlation with DNA damage. Int J Contemp Pediatr. 2016;3:768-72. doi: 10.18203/2349-3291.ijcp20161853.

9. Meena BS, Agarwal BK, Mishra A, Kumar M. Correlation between oxidative stress and antioxidant in diabetic nephropathy. Int J Res Med Sci. 2020;4:26-9. 
10. Ghodake SR, Suryakar AN, Ankush RD, Katkam RV, Shaikh K, Katta AV. Role of free radicals and antioxidant status in childhood nephrotic syndrome. Indian J Nephrol. 2011;21(1):37-40. doi: 10.4103/0971-4065.78062, PMID 21655168.

11. Lash LH. Role of glutathione transport processes in kidney function. Toxicol Appl Pharmacol. 2005;204(3):329-42. doi: 10.1016/j.taap.2004.10.004, PMID 15845422.

12. Buege JA, Aust SD. Microsomal lipid peroxidation. Methods Enzymol. 1978;52:302-10. doi: 10.1016/s0076-6879(78) 52032-6, PMID 672633.

13. Marklund S, Marklund G. Involvement of the superoxide anion radical in the autoxidation of pyrogallol and a convenient assay for superoxide dismutase. Eur J Biochem. 1974;47(3):469-74. doi: 10.1111/j.1432-1033.1974.tb03714.x, PMID 4215654.

14. Jollow DJ, Mitchell JR, Zampaglione N, Gillette JR. Bromobenzene-induced liver necrosis. Protective role of glutathione and evidence for 3, 4-bromobenzene oxide as the hepatotoxic metabolite. Pharmacology. 1974;11(3):151-69. doi: 10.1159/000136485, PMID 4831804.

15. Duann P, Datta PK, Pan C, Blumberg JB, Sharma M, Lianos EA. Superoxide dismutase mimetic preserves the glomerular capillary permeability barrier to protein. J Pharmacol Exp Ther. 2006;316(3):1249-54. doi: 10.1124/jpet.105.092957, PMID 16303918.

16. Ghodake SR, Suryakar AN, Ankush RD, Katkam RV, Shaikh K, Katta AV. Role of free radicals and antioxidant status in childhood nephrotic syndrome. Indian J Nephrol. 2011;21(1):37-40. doi: 10.4103/0971-4065.78062, PMID 21655168.

17. Kamireddy R, Kavuri S, Devi S, Vemula H, Chandana D, Harinarayanan S, James R, Rao A. Oxidative stress in pediatric nephrotic syndrome. Clin Chim Acta. 2002;325(1-2):147-50. doi: 10.1016/s0009-8981(02)00294-2, PMID 12367779.

18. Nagata M. Podocyte injury and its consequences. Kidney Int. 2016;89(6):1221-30. doi: 10.1016/j.kint.2016.01.012, PMID 27165817.

19. Rajendiran D, Packirisamy S, Gunasekaran K. A review on the role of antioxidants in diabetes. Asian J Pharm Clin Res. 2018;11(2):48-53. doi: 10.22159/ajpcr.2018.v11i2.23241.

20. Sireesha K, Rao SP. Oxidative stress and diabetes: an overview. Asian J Pharm Clin Res. 2015;8:15-9.

21. Kohen R, Nyska A. Oxidation of biological systems: oxidative stress phenomena, antioxidants, redox reactions, and methods for their quantification. Toxicol Pathol. 2002;30(6):620-50. doi: 10.1080/01926230290166724, PMID 12512863.

22. Túri S, Németh I, Torkos A, Sághy L, Varga I, Matkovics B, Nagy J. Oxidative stress and antioxidant defense mechanism in glomerular diseases. Free Radic Biol Med. 1997;22(1-2):161-8. doi: 10.1016/s0891-5849(96)00284-5, PMID 8958140.
23. Templar J, Kon SP, Milligan TP, Newman DJ, Raftery MJ. Increas ed plasma malondialdehyde levels in glomerular disease as determined by a fully validated HPLC method. Nephrol Dial Transplant. 1999;14(4):946-51. doi: 10.1093/ndt/14.4.946, PMID 10328476.

24. Pavlova EL, Lilova MI, Savov VM. Oxidative stress in children with kidney disease. Pediatr Nephrol. 2005;20(11):1599-604. doi: 10.1007/s00467-005-1990-x, PMID 16001281.

25. McCord JM. Human disease, free radicals, and the oxidant/antioxidant balance. Clin Biochem. 1993;26(5):351-7. doi: 10.1016/0009-9120(93)90111-i, PMID 8299205.

26. Koninsberger JC, Asbeck BS, Iassen E. Copper zinc-superoxide dismutase and hydrogen peroxide: A hydroxyl radical generating system. Clin Chim Acta. 1994;23:51-61.

27. Bülbul M, Oner A, Demircin G, Erdogan O. Oxidative stress in children with acute glomerulonephritis. Ren Fail. 2008;30(2):209-14. doi: 10.1080/08860220701813319, PMID 18300123.

28. Demircin G, Oner A, Unver Y, Bulbul M, Erdogan O. Erythrocyte superoxide dismutase activity and plasma malondialdehyde levels in children with Henoch Schönlein purpura. Acta Paediatr. 1998;87(8):848-52. 10.1080/080352598750013617, PMID 9736232.

29. Mayura AK, Suparma MB, Pratima K. Role of antioxidants and nutrition in oxidative stress. Int J Appl Pharm. 2015;7:1-4.

30. Meister A, Anderson ME. Glutathione. Annu Rev Biochem. 1983;52:711-60. doi: 10.1146/annurev.bi.52.070183.003431, PMID 6137189.

31. Ghodake SR, Suryakar AN, Kulhalli PM, Padalkar RK, Shaikh AK. A study of oxidative stress and influence of antioxidant vitamins supplementation in patients with major depression. Curr Neurobiol. 2012;3:107-11.

32. Mistry KN, Dabhi BK, Joshi BB. Evaluation of oxidative stress biomarkers and inflammation in pathogenesis of diabetes and diabetic nephropathy. Ind J Biochem Biophys. 2020;57:45-50.

33. Beaman M, Birtwistle R, Howie AJ, Michael J, Adu D. The role of superoxide anion and hydrogen peroxide in glomerular injury induced by puromycin aminonucleoside in rats. Clin Sci (Lond). 1987;73(3):329-32. doi: 10.1042/cs0730329, PMID 2820648.

34. Chen HC, Tomino Y, Yaguchi Y, Fukui M, Yokoyama K, Watanabe A, Koide H. Oxidative metabolism of polymorphonuclear leukocytes (PMN) in patients with IgA nephropathy. J Clin Lab Anal. 1992;6(1):35-9. doi: 10.1002/jcla.1860060108, PMID 1542082.

35. Vega-Warner V, Ransom RF, Vincent AM, Brosius FC, Smoyer WE. Induction of antioxidant enzymes in murine podocytes precedes injury by puromycin aminonucleoside. Kidney Int. 2004;66(5):1881-9. doi: 10.1111/j.1523-1755.2004.00962.x, PMID 15496159. 